\title{
Análise neo-schenkeriana e reduções De ordem prática como recursos analíticos ao repertório de ragtime e o exemplo de The Entertainer, de Scott Joplin
}

Alexy Viegas

(USP)

Resumo: Neste trabalho é proposta uma análise do ragtime The Entertainer (1902), de Scott Joplin, sob a metodologia de análise proposta por Schenker, conforme Fraga (2009) e reduções de ordem prática. Em The Entertainer, identifica-se a presença de diversas técnicas de progressão linear, como prolongamento melódico, ascensão inicial, desdobramento, transferência de registro, superposição, ligação e substituição. Este estudo leva a uma reflexão sobre a utilização desta metodologia de análise para o estudo de peças de música popular compostas no final do século XIX e início do século XX.

Palavras-chave: Ragtime. Análise neo-schenkeriana. Análise musical. Teoria musical.

PRACTICAL NEO-SCHENKERIAN REDUCTIONS AS RAGTIME ANALYTICAL RESOURCES AND THE EXAMPLE OF THE ENTERTAINER, BY SCOTT JOPLIN

Abstract: This paper proposes an analysis of The Entertainer (1902), by Scott Joplin, under the methodology proposed by Schenker and recently reviewed by Fraga (2009) with music reductions. In The Entertainer, is identified the presence of various techniques of linear progression as melodic extension, initial ascent, unfolding, register transfer, superposition, connection and replacement. This study leads to a reflection on the use of this method of analysis for the study of popular music composed in the late nineteenth century and early twentieth century.

Keywords: Ragtime. Schenkerian analysis. Music analysis. Music theory. 
Descrita como uma teoria em que "protótipos mentais moldam a percepção musical" (SNARRENBERG apud ROTHSTEIN, 2001, p. 205), a fundamentação teórica de Schenker tem servido a mais de um século como suporte ao estudo da música da Europa Ocidental conforme sua prática realizada entre os séculos XVIII e XIX. Revisões dos conceitos originais de Schenker foram realizadas por analistas musicais como Salzer (1962), alinhados à vertente chamada neo-schenkeriana, resultando em pressupostos teóricos aplicáveis ao repertório pós-tonal.

No campo da música popular, destacam-se alguns trabalhos que dialogam com conceitos neo-schenkerianos, que vão do jazz ao rock, como Gershwin (GILBERT, 1984), Bill Evans (LARSON, 1998), Wayne Shorter (STRUNK, 2005), Beatles (MOORE, 1993), Bob Dylan e Jimi Hendrix (ZAK III, 2004), Radiohead e King's X (CAPUZZO, 2009). No entanto, curiosamente não são encontrados trabalhos que tenham se dedicado à análise de ragtime sob a metodologia neoschenkeriana, tendo em vista o contexto tonal em que se insere.

No presente trabalho o objetivo é experimentar a metodologia neoschenkeriana que Orlando Fraga apresenta didaticamente na publicação intitulada Progressão linear: uma breve introdução à teoria de Schenker (FRAGA, 2009), para a análise de música popular norte-americana composta na virada do século XIX para o XX, particularmente o ragtime. O livro de Fraga traz recursos metodológicos voltados ao estudo de obras tonais e que também têm sido aplicados ao repertório popular, o que nos sugere a possibilidade de analisarmos obras do ragtime sob esta perspectiva. Somam-se a isso, reduções comumente praticadas na música popular, a que denominaremos "reduções de ordem prática" no presente trabalho (cf. Fig. 1, 4, 5, 6, 7, 8, 9, 11).

Tido como a principal manifestação musical no negro norte-americano entre meados da década de 1890 até a ascensão do jazz e tendo como seu principal expoente o compositor Scott Joplin (1867-1917), o ragtime é derivado 
das marchas das bandas militares, coon songs' e cakewalks². Através do hibridismo entre danças clássicas europeias e elementos rítmicos africanos, o ragtime pode ser descrito como:

Um estilo de música popular, essencialmente americano, que prosperou de 1896 a 1918, aproximadamente. Sua principal característica é o ritmo ragged $^{3}$ ou sincopado. Embora hoje seja mais comumente considerado um estilo pianístico, durante o período citado o termo ragtime também se referia à música instrumental, à vocal e à dança. As melhores peças instrumentais de ragtime manifestaram um pensamento musical sofisticado e exigiam considerável desenvoltura técnica do performer para que fosse realizada em sua completude (BERLIN, 2001, p. 756). ${ }^{4}$

Reconhecendo a escassez de estudos musicológicos sobre a análise musical de ragtime, nosso trabalho, de caráter experimental, visa trabalhar os tópicos abordados na recente publicação de Fraga, propondo reduções musicais a fim de ouvi-las como exercícios de análise. Composta em 1902. The Entertainer, de Scott Joplin, é provavelmente a peça do gênero mais prontamente reconhecível pelo ouvinte pouco habituado com o ragtime. Sua forma está organizada em introdução, A, B, A, C, D, ponte e coda.

Nesta primeira parte de nosso artigo, iniciaremos a busca por técnicas de prolongamento e progressão linear em toda a obra, visando discutir os procedimentos utilizados até a chegada às reduções finais das seções. Serão utilizados exemplos do arranjo original de The Entertainer, trabalhados em tópicos específicos. Visando contribuir com a interpretação musical e a discussão

1 Segundo Dennison (2001, p. 392), um gênero da canção cômica norte-americana, popularizada por volta de 1880 até o final da Primeira Guerra Mundial, com letras que propunham o modo de falar dos negros norte-americanos. O termo "coon" era usado depreciativamente contra os negros da época.

2 "O cakewalk originalmente foi um fenômeno nas plantações, onde casais de escravos, utilizando seus trajes de domingo, disputavam um bolo. O prêmio era dado ao casal que realizasse o passo mais elegante e expansivo." (SHAW, 1986, p. 43-44, tradução nossa).

${ }^{3}$ Termo em inglês que se refere à sincopa de ragtime.

4 "A style of popular music, chiefly American, that flourished from about 1896 to 1918. Its main identifying trait is its ragged or syncopated rhythm. While today it is most commonly thought of as a piano style, during the ragtime period the term also referred to other instrumental music, to vocal music and to dance. The best instrumental ragtime pieces manifested sophisticated musical thought and demanded considerable technical facility of a performer for their fullest realization." (BERLIN, 2001, p. 756, tradução nossa). 
acadêmica a respeito de The Entertainer e de outras peças do gênero, serão abordados conceitos trazidos por Fraga (2009) como fundamentação. Para uma melhor compreensão musical dos tópicos trazidos por este trabalho, encorajamos que as figuras e exemplos aqui apresentados sejam executadas ao piano.

\section{Prolongamento melódico}

A análise de The Entertainer nos revela diversas técnicas de progressão linear, muitas delas fundamentadas sob o princípio de prolongamento melódico. Em alguns trechos, uma única nota é prolongada por vários compassos e frases, fazendo conexão com estruturas que ainda estão por vir. Um recurso amplamente utilizado nesta peça é a diminuição, aquilo que Fraga (2009, p. 20) conceitua como "passagens ornamentais constituídas com notas de passagem, tons vizinhos, apojaturas, saltos consonantes, retardos, entre outros, que formam uma unidade linear".

Exemplificando esta técnica, a figura abaixo (Fig. 1) apresenta o texto musical original, extraído do início da seção B, e duas reduções de ordem prática. Percebe-se que a anacruse serve como uma chegada à nota estrutural Sol, sendo que a nota de apojatura Lá atua como prolongamento desta nota Sol. Na segunda metade do compasso as notas Mi-Fá-Fá\# repetem o motivo da anacruse, funcionando como uma frase de prolongamento da nota Sol, chegando na mesma nota Sol. A última redução demonstra que a nota Sol é de importância estrutural ao trecho. ${ }^{5}$

\footnotetext{
${ }^{5}$ Para que não haja confusão ao leitor iniciante na teoria neo-schenkeriana, vale lembrar que as ligaduras apresentadas nos exemplos não são de expressão, e sim ferramentas analíticas que servem para representar prolongamentos de notas fundamentais.
} 
Fig. 1: Prolongamento. Joplin, The Entertainer (comp. 22-23).
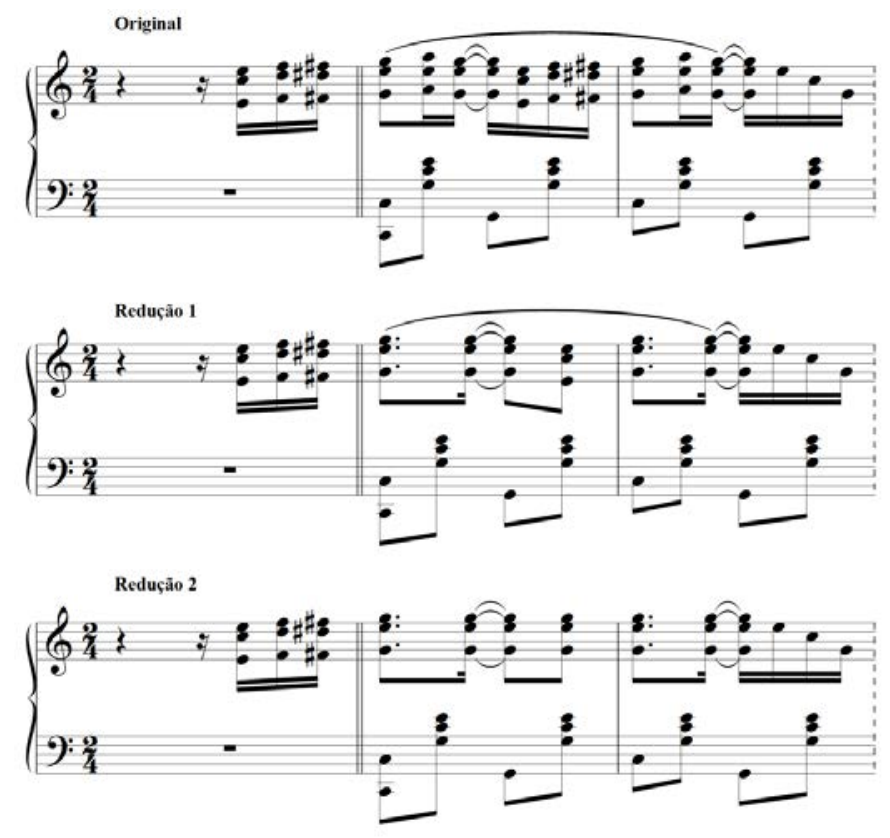

\section{Ascensão inicial}

De acordo com Fraga (2009, p. 34), a ascensão inicial é “um movimento ascendente por grau conjunto ou arpejo de tríade (ou ainda uma combinação de ambos), que parte de uma nota da tríade de tônica em direção à primeira nota da LF6 (nota inicial)". Em The Entertainer, podemos observar com alguma recorrência trechos onde a ascensão inicial se faz presente, e ainda com um papel significativo: serve como uma espécie de "introdução", ou um caminho à primeira nota da linha fundamental.

No exemplo abaixo (Fig. 2), após algumas reduções estruturais pode-se observar que a ascensão inicial ocorre entre o compasso 5 (com sua anacruse) até

\footnotetext{
6 “Linha Fundamental (LF) é uma representação abstrata da linha melódica, atingida por sucessivas depurações das camadas ou estruturas de uma melodia, cujo componente básico é constituído de repetição e ornamentação. A LF conecta as notas estruturais de uma ou mais harmonias. Cada grau da escala representado na LF é indicado por um acento circunflexo acima do número que o indica" (FRAGA, 2009, p. 29).
} 
o final do compasso 6 , onde identifica-se a nota $\mathrm{Mi}$ (primeira nota do compasso 7) como uma nota estrutural ao trecho.

Fig. 2: Ascensão inicial. Joplin, The Entertainer (comp. 5-8).

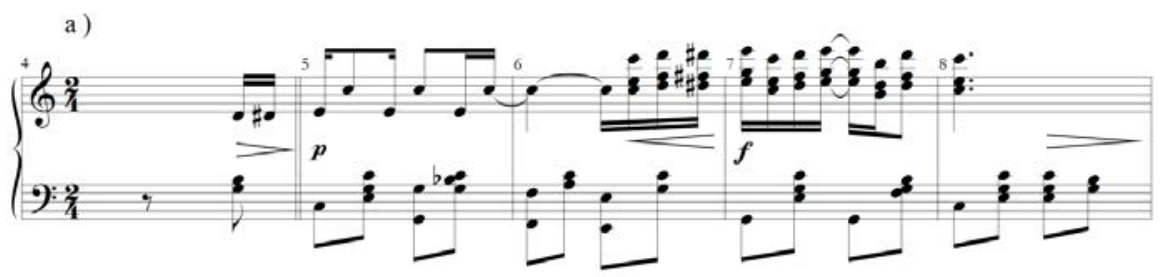

b)

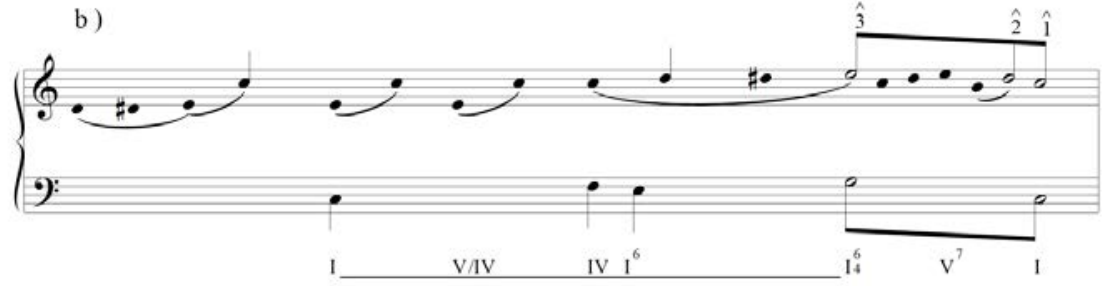

c)
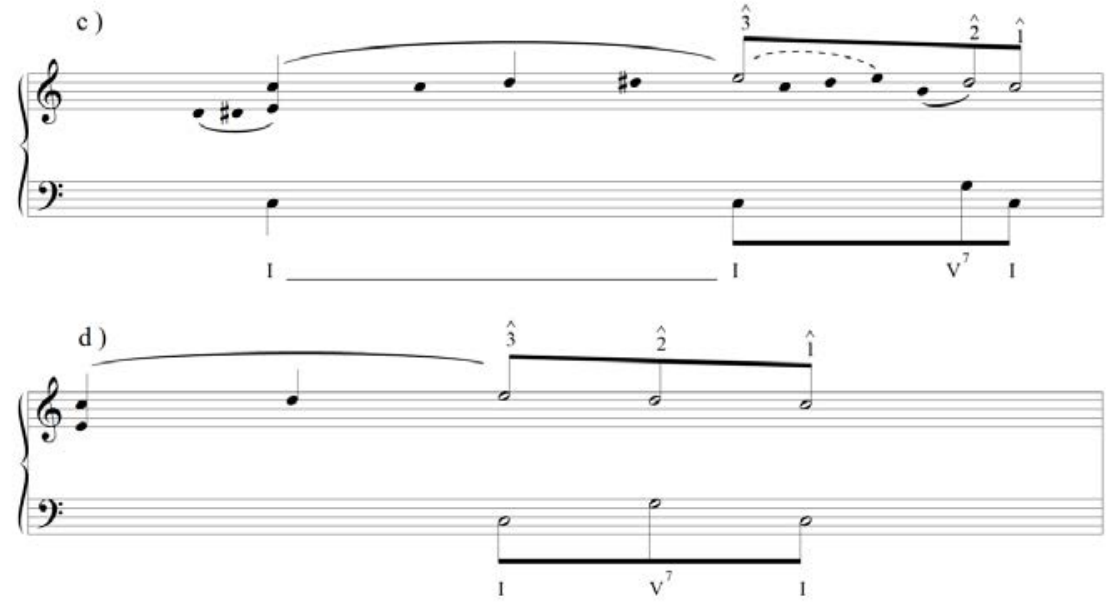

Outro momento onde se identifica a ascensão inicial é no início da seção D, mas apenas nas camadas mais profundas de redução - antes de detectá-la é preciso resolver questões de desdobramentos, notas de passagem e prolongamentos. As notas Dó-Mi-Dó, pertencentes ao arpejo do acorde da tonalidade, são procedidas por Lá e Fá\#, notas que bordam e alcançam a nota Sol, esta última de importância estrutural na seção. Desta forma temos o um arpejo da 
tríade Dó maior caracterizando a ascensão inicial. A ilustração abaixo demonstra o plano de fundo do trecho:

Fig. 3: Ascensão inicial na seção D. Joplin, The Entertainer (comp. 76-92).

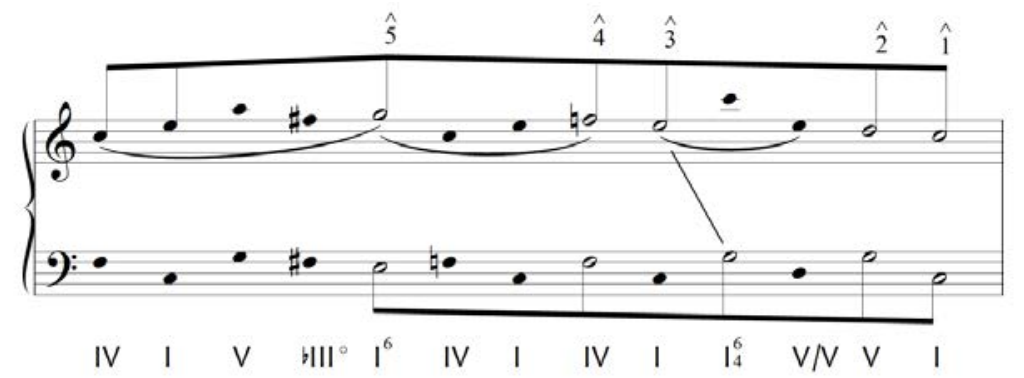

\section{Desdobramento}

De acordo com Fraga (2009, p. 35), desdobramento é o "resultado do desmembramento de um intervalo harmônico", sendo "uma técnica conceitual, pois horizontaliza um intervalo que, em um plano estrutural mais fundo, é simultâneo". Em referência a esta técnica, destacamos haver inúmeras ocorrências em trechos de melodias de ragtime nos quais duas notas de um acorde são alternadas sob uma rítmica sincopada (Fig. 4 e 5).

Nas reduções de ordem prática que formam esta análise, a rítmica sincopada é simplificada, traçando o caminho inverso. Temos aqui dois exemplos desta técnica. O primeiro (Fig. 4) mostra que um intervalo melódico ascendente Mi-Dó, que se repete por três vezes, torna-se um intervalo harmônico na redução, articulado no primeiro e no segundo tempo do compasso:

Figura 4: Desdobramentos. Joplin, The Entertainer (comp. 5-7).

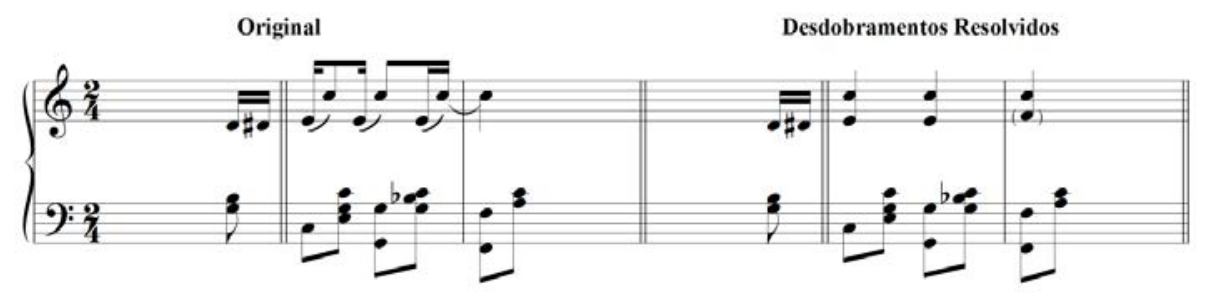


O segundo exemplo (Fig. 5), extraído da seção C, assemelha-se ao trecho acima, porém é apresentado em outro momento e em outra tonalidade. O intervalo melódico descendente Dó-Lá se torna um intervalo harmônico, articulado no primeiro e segundo tempos do compasso. É interessante observar que o intervalo é repetido também por três vezes, apesar de a rítmica ser um pouco diferente. Esta repetição do mesmo intervalo articulado por três vezes no mesmo compasso é algo significativo a se observar na análise de The Entertainer e no repertório de ragtime de forma geral:

Fig. 5: Desdobramentos. Joplin, The Entertainer (comp. 33-34).

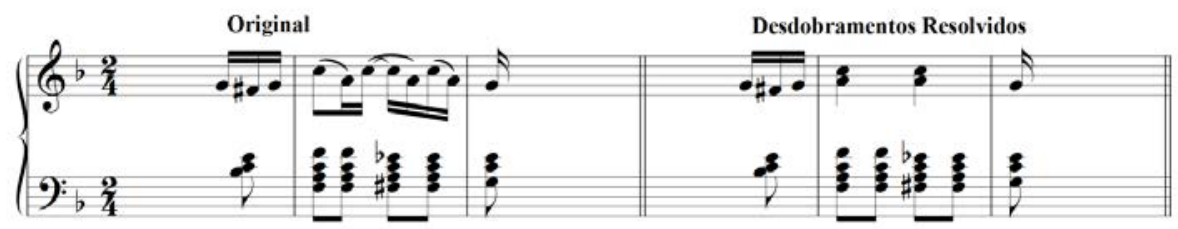

Do processo de identificação de desdobramentos decorre a eliminação de notas auxiliares, como notas de passagem e bordaduras, especialmente em momentos de subida ou descida escalar. Após a eliminação das notas auxiliares, ficam apenas os fatores formativos do acorde, sob um perfil de desdobramento. A partir deste momento, pode-se dar início à redução que irá eliminar os desdobramentos, transformando os intervalos horizontais em verticais. O exemplo a seguir (Fig. 6) traz reduções de ordem prática que mostram o trecho original e as reduções que alcançam um plano de fundo. A primeira redução elimina as nota auxiliares, nesse caso a nota Ré, e identifica os desdobramentos intervalares demonstrados pelo traço (Dó-Sol, Mi-Dó, Mi-Dó, na primeira redução). A segunda redução dispõe estes intervalos de forma vertical, adaptando a rítmica aos pontos fortes do compasso (colcheias e semínimas em 2/4, fórmula de compasso típica de ragtime). É neste momento do processo de redução que as melodias perdem sua característica rítmica e sincopada, dando espaço a uma redução que pode soar "artificial", ou "crua" (contudo, questões estruturais tornam-se mais evidentes). Por fim, a terceira redução "resume" a segunda, revelando o que está por trás da superfície musical: 
Fig. 6: Desdobramentos. Joplin, The Entertainer (comp. 79).

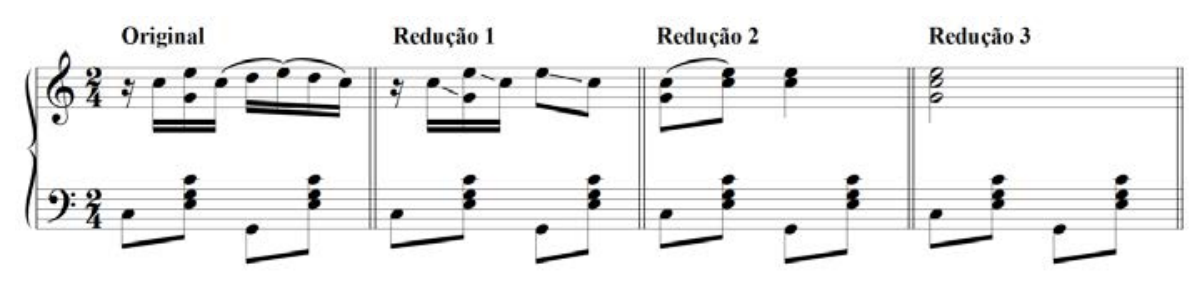

\section{Transferência de registro}

Segundo Fraga (2009, p. 40), a transferência de registro é uma técnica de "transferência direta de uma nota ou mais, do registro agudo para o grave ou vice-versa", e apesar de estar associada ao salto de oitava, "esta não é a (sua) única relação, e outros intervalos são possíveis". Pode ser interpretada como uma técnica de prolongamento de melodias e linhas estruturais.

No exemplo abaixo (Fig. 7), é possível identificar um exemplo da técnica de transferência de registro pela descida melódica a partir da nota Sol, passando por notas do arpejo de Dó maior até alcançar a nota Sol uma oitava abaixo (segundo tempo do segundo compasso do exemplo). Durante o terceiro compasso, sob uma harmonia de IV e iv, identifica-se uma melodia de graus conjuntos que funciona como prolongamento, novamente da nota $\mathrm{Sol}^{7}$, que dura da última semicolcheia do segundo compasso, até a primeira nota Sol do quarto compasso. Observa-se que no quarto compasso do exemplo a passagem Sol-MiFá-Sol revela um retorno ao registro obrigatório ${ }^{8}$. A redução de ordem prática abaixo aponta para o primeiro tempo do quarto compasso sendo, em um plano mais profundo, apenas uma nota Sol subindo uma oitava:

\footnotetext{
7 Poderemos observar nas reduções finais deste trabalho que esta passagem está relacionada com um movimento cruzado, em que a melodia está subentendida na harmonia da mão esquerda - IV iv - através das notas Lá e Láb.

8 "Registro no qual se aloja a LF e que serve de referência quando uma voz se desloca para outro registro" (FRAGA, 2009, p. 39).
} 
Fig. 7: Transferência de registro. Joplin, The Entertainer (comp. 22-25).

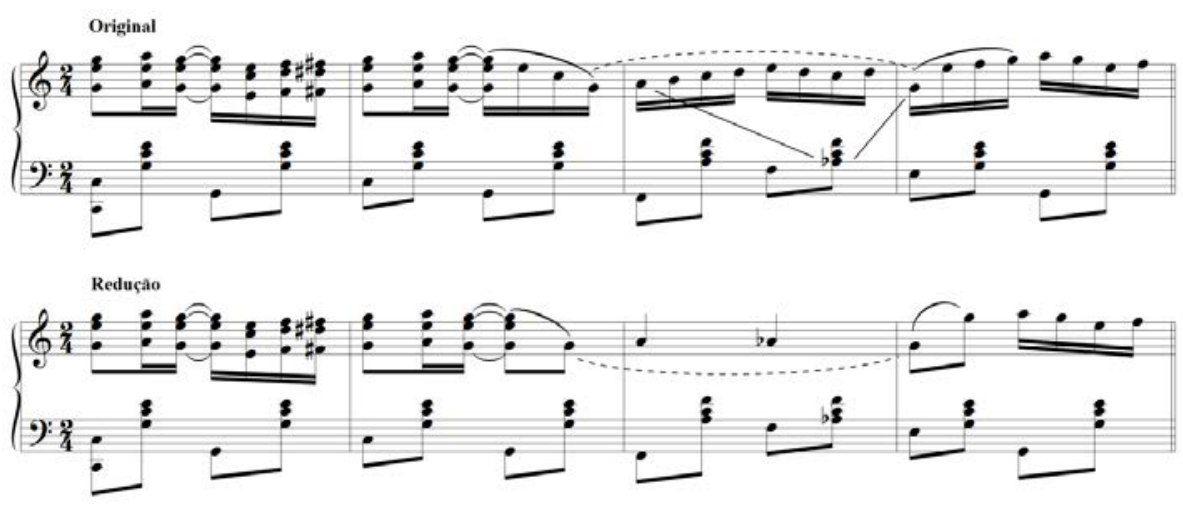

\section{Transferência de registro através de dobramentos em oitava}

Uma característica peculiar do gênero ragtime é o frequente aparecimento de melodias oitavadas. A oitava em ragtime consiste em um recurso expressivo, utilizado amplamente junto às mais variadas técnicas de composição e arranjo, como a variação de uma repetição literal, um destaque ou um reforço melódico. Na textura homofônica do ragtime, aparece de maneira recorrente, dobrando a linha melódica, reforçando os baixos do acompanhamento, ora em ambos. Quando utilizada na linha do baixo, tende a ampliar a sonoridade da mão esquerda, provocando melhor inteligibilidade harmônica e da linha mais grave. Se utilizada na mão direita, onde quase sempre os materiais temáticos de ragtime são apresentados, geralmente possui a função de destacar a melodia principal ou intensificar em termos dinâmicos a sonoridade da melodia.

A figura abaixo (Fig. 8) traz uma redução de ordem prática que representa esta questão. A melodia original da mão direita é reduzida através da eliminação da oitava mais aguda, sendo que as notas que preenchem a oitava em intervalos de terça (a partir da oitava de baixo) também são eliminadas, restando, na redução, apenas a melodia principal: 
Fig. 8: Transferência de registro. Joplin, The Entertainer (comp. 6-8).

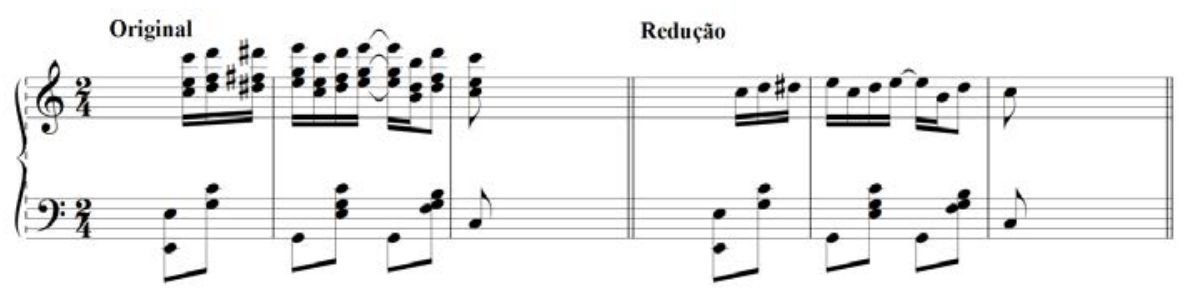

O caso abaixo é similar ao exemplo acima. Apesar de estarem em seções diferentes, pode-se observar certa similaridade motívica, sobretudo no primeiro compasso (anacruse). Neste exemplo, a melodia da oitava de baixo foi eliminada, pois a continuação do trecho aponta para uma continuidade melódica apenas na oitava de cima. O princípio de redução de ordem prática, porém, é o mesmo. As notas que preenchem a oitava em intervalos de terça (a partir da oitava de cima) também são eliminadas, restando, na redução, apenas a melodia principal do trecho, no registro obrigatório:

Fig. 9: Transferência de registro. Joplin, The Entertainer (comp. 21-23).

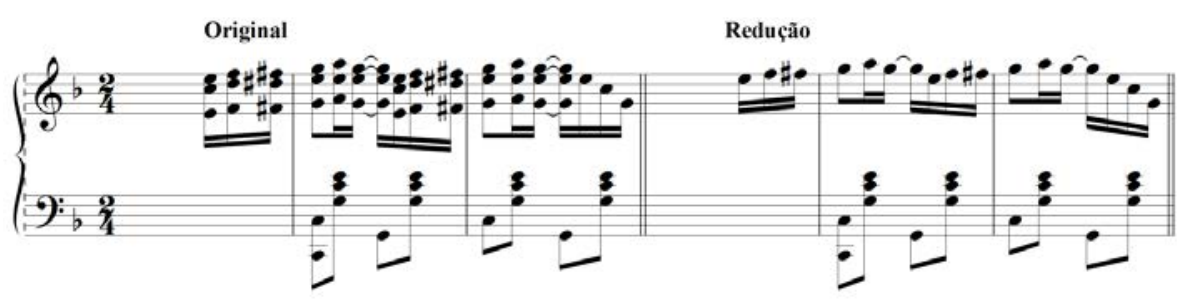

\section{Superposição}

Segundo Fraga (2009, p. 42), “a superposição acontece quando uma ou mais vozes internas aparecem acima da voz principal ou registro obrigatório".

Ainda de acordo com o autor, "é muito comum a superposição aparecer apenas no plano frontal ou no plano médio". 
No exemplo abaixo, pode-se observar que o plano de fundo da Seção C de The Entertainer apresenta uma linha fundamental interrompida em um primeiro momento, que se conclui em cadência perfeita no final do trecho. As notas circuladas em vermelho prolongam a linha fundamental e caracterizam a técnica de superposição.

Fig. 10: Superposição, na Seção C. Joplin, The Entertainer (comp. 55-71).

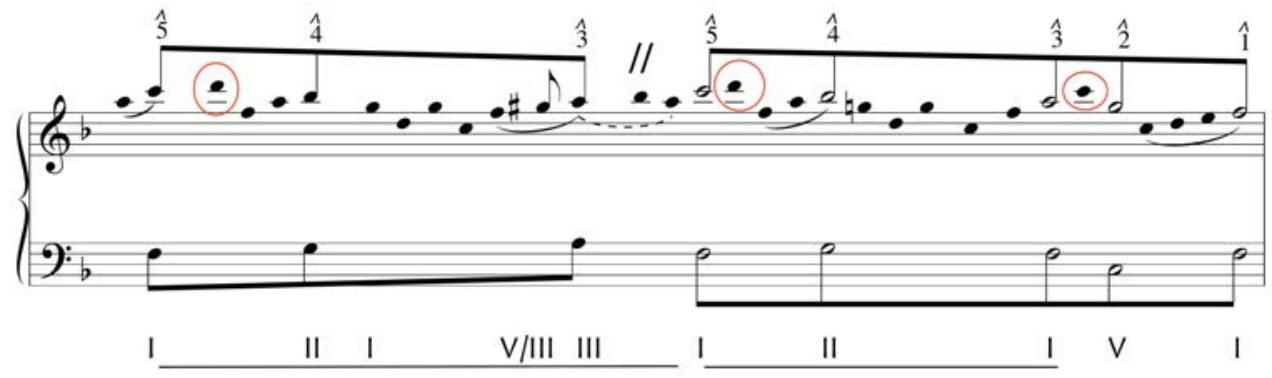

\section{Ligação}

Como prevê Fraga, a ligação é uma “técnica de associação motívica onde uma nova frase repete a ideia motívica da frase anterior, seja para dar continuidade a esta ou iniciar algo novo" (2009, p. 52).

Observa-se no exemplo abaixo, extraído da seção $A$, que a técnica de ligação está presente. O motivo inicial Ré-Ré\#-Mi é repetido no terceiro compasso do exemplo, quando encontramos as notas Dó-Ré-Ré\#-Mi, uma oitava acima. Apesar de o motivo inicial não apresentar a nota Dó, ela está incluída entre parênteses por estar subentendida e sugerida pela própria tonalidade, caracterizando o mesmo perfil melódico anacrúsico da cadência perfeita do quarto compasso do exemplo. Reforça esta ideia o fato de as notas Ré-Ré\#-Mi estarem na mesma posição métrica no compasso. A figura abaixo destaca o motivo entre parênteses: 
Fig. 11: Ligação. Joplin, The Entertainer (comp. 5-8).
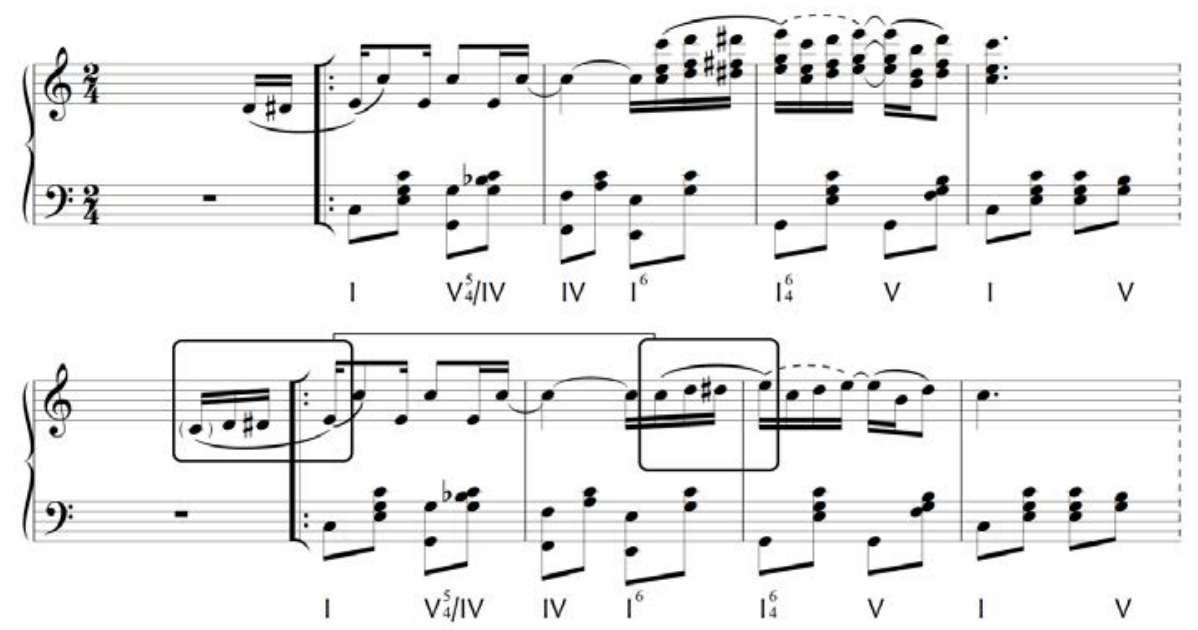

\section{Substituição}

Como atesta Fraga (2009, p. 46), a substituição “ocorre quando o contexto melódico ou harmônico exige uma certa nota e esta é substituída por razões puramente composicionais".

A figura 11 (acima) demonstra um caso peculiar em que a nota está omitida - ou substituída pelo silêncio - usando a grafia tradicional de substituição (nota entre parênteses). Na anacruse do primeiro compasso, temos as notas RéRé\#, que alcançam a nota Mi. A análise aponta uma nota Dó ausente que precede o primeiro grupo de notas. Esta conclusão é tomada devido à estrutura similar da frase na primeira cadência perfeita (compasso 3 do exemplo), como demonstrada na técnica de ligação.

\section{Linha fundamental}

Após este levantamento e aplicação de técnicas de prolongamento e progressão linear, a possibilidade de encontrarmos uma linha fundamental (Urlinie) entre seções completas de um ragtime torna-se mais próxima. Em The 
Entertainer temos 4 seções: as duas primeiras e a última estão na região da tônica (I), enquanto que a terceira seção está na subdominante (IV). A tonalidade da dominante (V) é afirmada apenas em alguns momentos dentro das seções da tonalidade principal, como nas cadências à dominante na metade das seções $\mathrm{A}$ e B. Mesmo assim é possível identificar uma linha descendente de terça (3-prg) ou de quinta (5-prg) em todas as seções, mesmo que a ausência de uma seção na dominante tenda a quebrar ou enfraquecer o desenho melódico descendente de uma suposta linha fundamental para toda a peça. Sendo assim, uma investigação atenta acerca das técnicas de progressão linear que produza gráficos separados de cada seção nos parece ser mais interessante. A partir de então podemos iniciar a busca por uma estrutura fundamental para a peça como um todo.

\section{Mão Esquerda e Baixo Fundamental}

Conforme Fraga (2009, p. 28), o “baixo fundamental (BF) é a linha no registro grave que dá suporte à melodia ou linha fundamental (LF)". Vale ressaltar que o gênero ragtime possui um apelo rítmico muito forte, e ao observarmos o perfil do baixo fundamental no exemplo de The Entertainer, percebemos que as linhas são basicamente rítmicas, articuladas na cabeça dos tempos fortes, e raramente possuem caráter contrapontístico de cruzamento de vozes e movimento contrário. A mão esquerda é um constante acompanhamento rítmico-harmônico articulado em colcheias. Por conta disso, pode-se observar que as linhas de baixo, na maioria das vezes, caracterizam-se por marcar a pulsação da peça e servir de sustentação para a melodia principal, que geralmente é sincopada. A linearidade do baixo é muitas vezes quebrada devido à necessidade rítmica de saltos que ocorrem entre os tempos fortes, intermediados pela presença de tríade do acorde do momento nos contratempos.

De forma geral, as linhas de baixo marcam a fundamental no primeiro tempo do compasso e a quinta, no segundo tempo. Isto faz com que a análise encontre um baixo fundamental com muitos saltos, até mesmo pelas frequentes cadências perfeitas que ocorrem ao longo de algumas seções, pois são raros são os 
momentos em que a mão esquerda dialoga com a mão direita no sentido de criar uma linha de contraponto. Um dos motivos para a esta ausência de movimento em grau conjunto está na obrigatoriedade rítmica do baixo. Rompendo com este padrão, o primeiro ritornello (casa 1) no final da seção A é um dos raros momentos em que o baixo se movimenta por graus conjuntos. Também se observa tal exceção no primeiro ritornello (casa 1) no final da seção B. Quanto ao recurso das inversões de baixo, percebe-se uma escrita que privilegia os acordes em estado fundamental; são raros os momentos onde se identifica acordes em inversão, como $I^{6}$ ou $I^{6}$ (algo que comprova esta ausência de linearidade no baixo fundamental é o fato de a seção D possuir apenas um acorde em inversão).

Constatamos, então, que o contraponto entre as vozes extremas (soprano e baixo) é pouco trabalhado. Por conta disso, uma análise estrutural de uma peça de ragtime poderia concentrar-se sobre a melodia principal e omitir a linha do baixo, representando-a através de graus harmônicos dos acordes em questão quando uma linha de baixo melodicamente significativa não fosse identificada. Contudo, mesmo observando pouca atividade contrapontística em peças do gênero, nossa metodologia opta por definir claramente as notas da linha do baixo acreditando que estas são referência no momento de relacionar os gráficos à partitura original.

\section{Estrutura fundamental}

Diante das duas opções de recorte do objeto a ser analisado: o recorte de um pequeno trecho (alguns compassos); ou o recorte de uma seção completa (16 compassos), a segunda opção se apresenta como um caminho mais interessante para análise de gêneros populares que apresentam esquemas formais recorrentes (como no caso do ragtime norte-americano, ou o choro brasileiro, que geralmente possuem 16 compassos em cada seção). Nosso trabalho se orienta desta forma, acreditando que assim chegaremos a resultados que relacionam o plano de fundo das seções com os detalhes ornamentais da superfície. Esta identificação das técnicas de progressão linear através de uma visão limitada a poucos compassos e 
atenta a detalhes do texto musical pode ser reveladora quanto às estruturas atuantes nos planos de fundo. A partir da conclusão desta etapa, podemos identificar alguma estrutura fundamental que possa estar atuando como uma edificação entre as seções, ou que seja recorrente entre as quatro seções da peça.

A investigação analítica sob o recorte de alguns compassos nos parece ser adequada especialmente em casos onde suspeitamos que uma estrutura fundamental possa estar atuando em um trecho curto, com potencial para se desenvolver através de outras técnicas de progressão linear durante a seção ou até mesmo durante toda a peça. Este é o caso da seção A de The Entertainer, que apresenta uma cadência perfeita logo nos primeiros quatro compassos através da progressão 321 (3-prg) vista na figura 2, reiterada na seção como um todo conforme a figura 12 .

Com um olhar mais amplo, é possível encontrarmos linhas fundamentais para as seções completas de 16 compassos na peça de Scott Joplin. Na seção C identificamos uma cadência à mediante no oitavo compasso, que funciona como interrupção, e uma cadência perfeita ao final da seção. Com isso, a seção C consiste em um discurso musical mais prolongado do que a seção A, que apresenta linha mais fragmentadas, decorrentes de cadências perfeitas em momentos não estruturais. Enquanto a seção $A$ apresenta três cadências perfeitas, a seção $C$ aponta apenas uma, em seu último compasso. A título de comparação, os gráficos abaixo representam o plano de fundo dos primeiros compassos de $\mathrm{A}$ e o plano de fundo de toda a seção C: 
Fig. 12: Estrutura Fundamental.
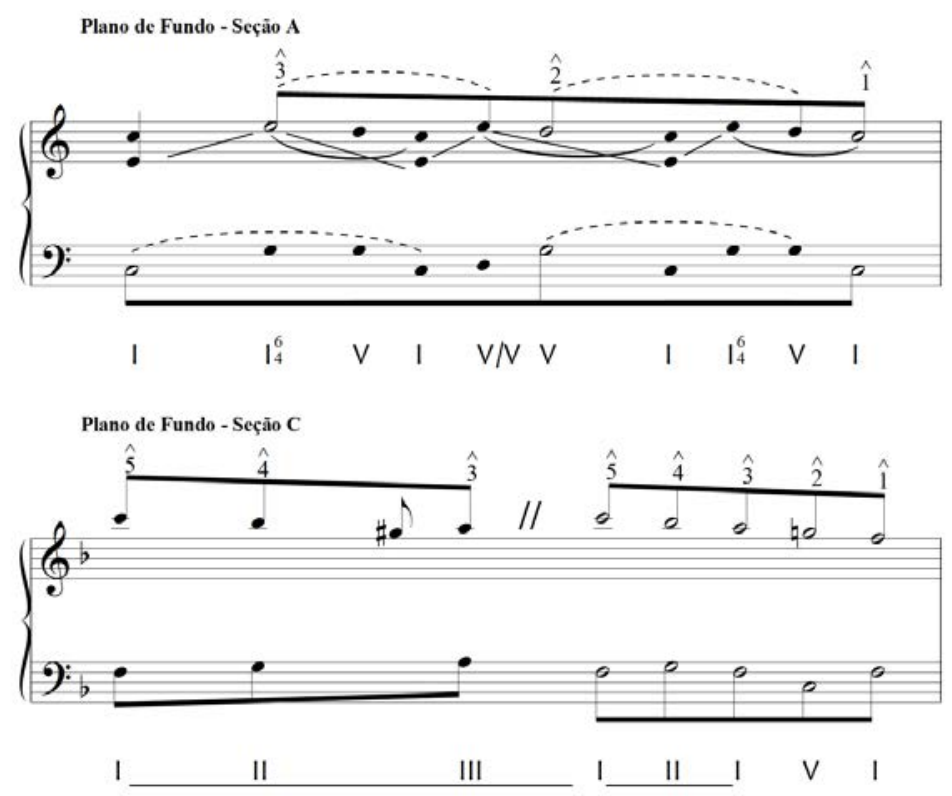

\section{Interrupção}

Segundo Fraga (2009, p. 49), a interrupção de linha fundamental é identificada quando "a tensão gerada pela primeira parte incompleta é resolvida no final da segunda parte, formando uma frase, período ou seção completos".

Esta técnica está presente na análise da seção C de The Entertainer. Após várias reduções, chega-se a uma estrutura fundamental que apresenta claramente uma progressão interrompida. Neste exemplo abaixo, a análise neo-schenkeriana revela uma progressão 54321 (5-prg), precedida de uma linha interrompida 5 4 3. A divisão da estrutura fundamental em tal disposição deve-se à presença de uma cadência ao III grau na metade da seção, que atua como uma interrupção da fluidez natural da linha, finalizando em cadência perfeita $V-I$ : 
Fig. 13: Interrupção

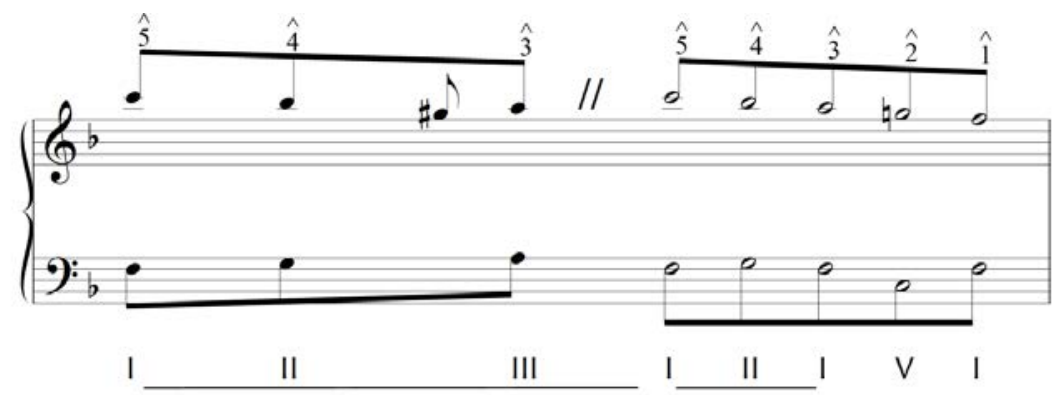

\section{Análise neo-schenkeriana como recurso de arranjo}

As técnicas de progressão linear podem produzir, além dos já tradicionais gráficos, partituras com elementos musicais reduzidos como apogiaturas, notas de passagem, ascensão inicial etc. Em alguns momentos, a eliminação das notas de passagem e apogiaturas na melodia da mão direita pode resultar em uma escrita pianística de acompanhamento típica dos arranjos de ragtime para conjunto. No exemplo abaixo, a redução da melodia dá origem a uma linha de piano, que executa o acorde de dó maior com a nota Mi na ponta devido à nota estrutural Mi identificada na melodia principal, tocada na figura abaixo pelo clarinete. No segundo tempo do segundo compasso acontece o mesmo, porém com a nota Sol. A linha tracejada indica a relação da melodia principal, tocada por um clarinete, com o arranjo de piano:

Fig. 14: Exemplo de arranjo.

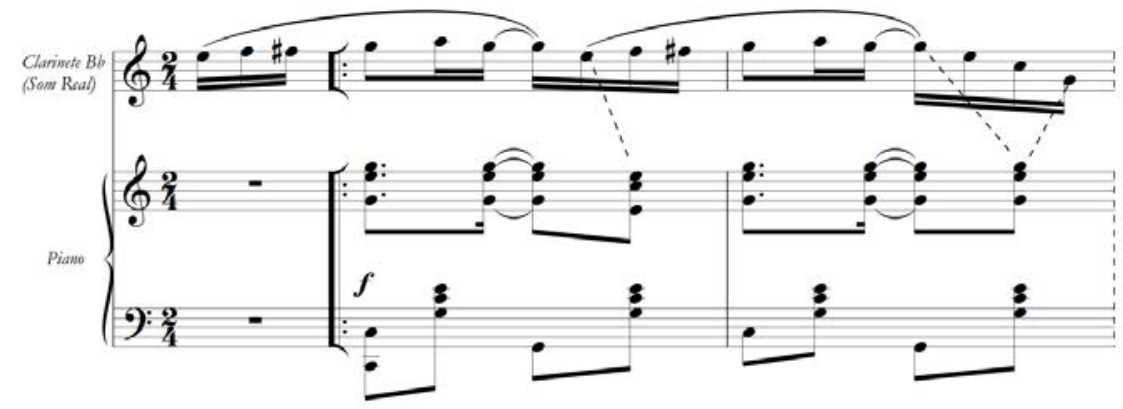




\section{Análise redutiva e a produção dos gráficos das seções}

A metodologia utilizada para criar reduções da partitura foi fundamentada nas técnicas de progressão linear e prolongamento da teoria neo-schenkeriana vistos na primeira parte do trabalho. Nessa proposta de criarmos partituras reduzidas de The Entertainer, a primeira redução de cada seção foi caracterizada pela eliminação de notas de passagem, bordaduras e escapadas. Após este primeiro procedimento, respeitou-se o seguinte roteiro para a elaboração das demais reduções:

Segunda etapa: Eliminação de notas repetidas e síncopes;

Terceira etapa: Simplificação de desdobramentos;

Quarta etapa: Simplificação das apojaturas resultantes das primeiras reduções em notas do acorde do momento;

Quinta etapa: Redução rítmica (adaptação do material resultante das primeiras reduções aos tempos fortes do compasso);

Sexta etapa: Eliminação das notas oitavadas e intermediárias (contralto).

Algumas seções necessitaram de um número maior de reduções até que obtivéssemos o material necessário para dar início à confecção dos gráficos. Foi o caso das seções A e D. As seções B e C exigiram, ao contrário das demais, poucas etapas redutivas. Em momentos mais simples de algumas seções, determinados parâmetros de redução foram utilizados ao mesmo tempo.

Reconhecemos que o leitor pouco acostumado com análise neoschenkeriana pode fazer confusão a respeito da produção das primeiras camadas de redução devido à especificidade do processo. Em caso de dúvida recomenda-se executar atentamente ao piano os gráficos produzidos, pois estes são sonoramente autoexplicativos. Basta comparar o exemplo em questão com a redução anterior ou posterior. Lembramos que algumas vezes, a execução musical dos gráficos pode não corresponder à rítmica das notas escritas (cabeças de notas vazadas ou pretas, por exemplo). Quanto à execução musical destes exemplos, não se faz necessária a reprodução da rítmica conforme representada pelos gráficos diferenciando colcheias e semínimas em planos de fundo, por exemplo. A proposta é que a execução musical dos gráficos sirva para exemplificar 
acusticamente as etapas do processo analítico neo-schenkeriano, verificando se os "protótipos mentais" em jogo realmente moldam nossa percepção musical.

Fig. 14: Plano frontal, médio e de fundo. Seção A.
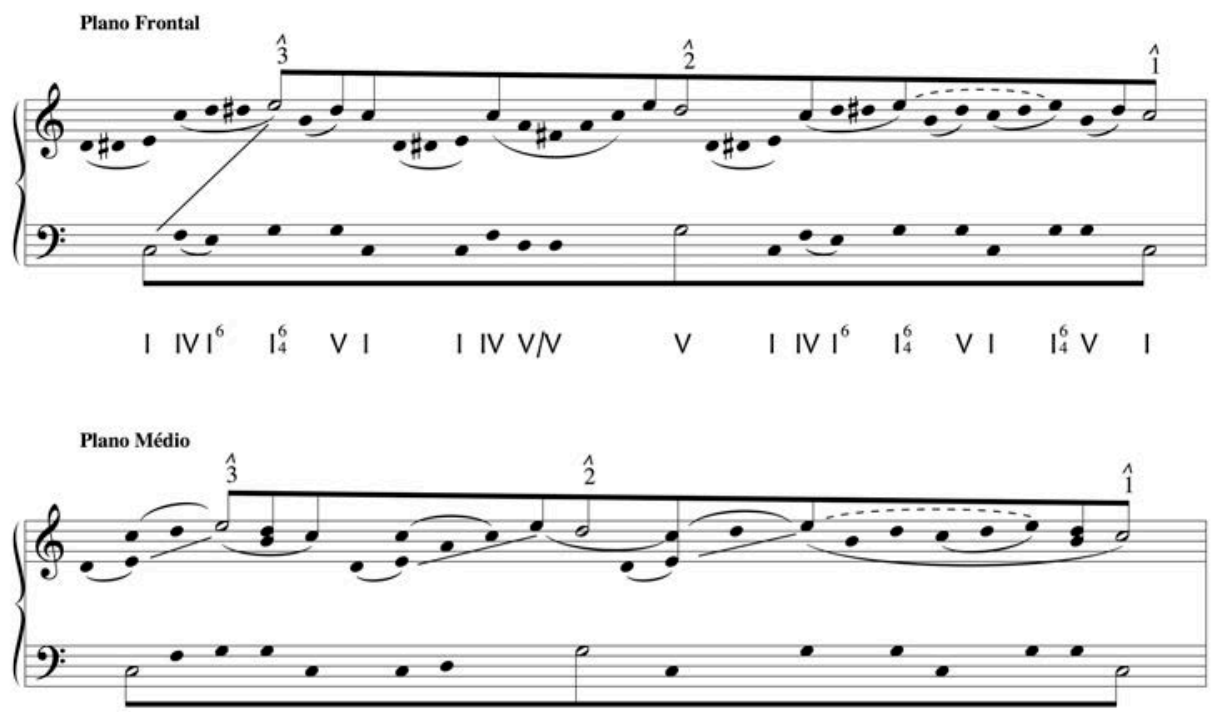

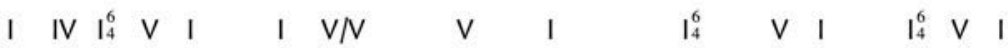

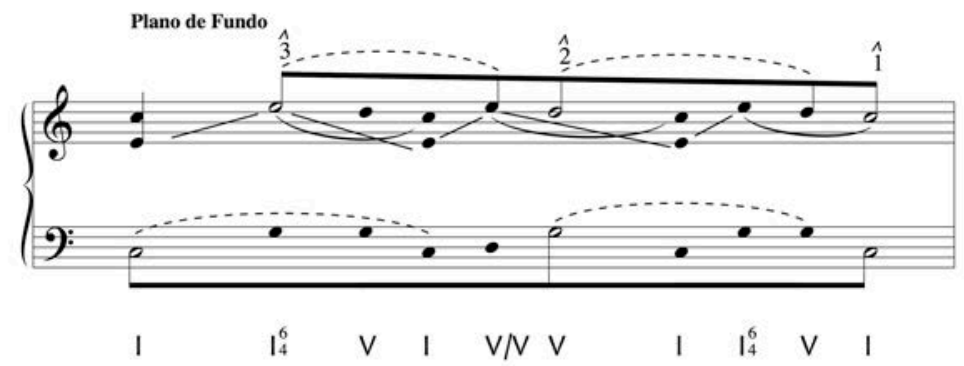


Fig. 15: Plano frontal, médio e de fundo. Seção B.
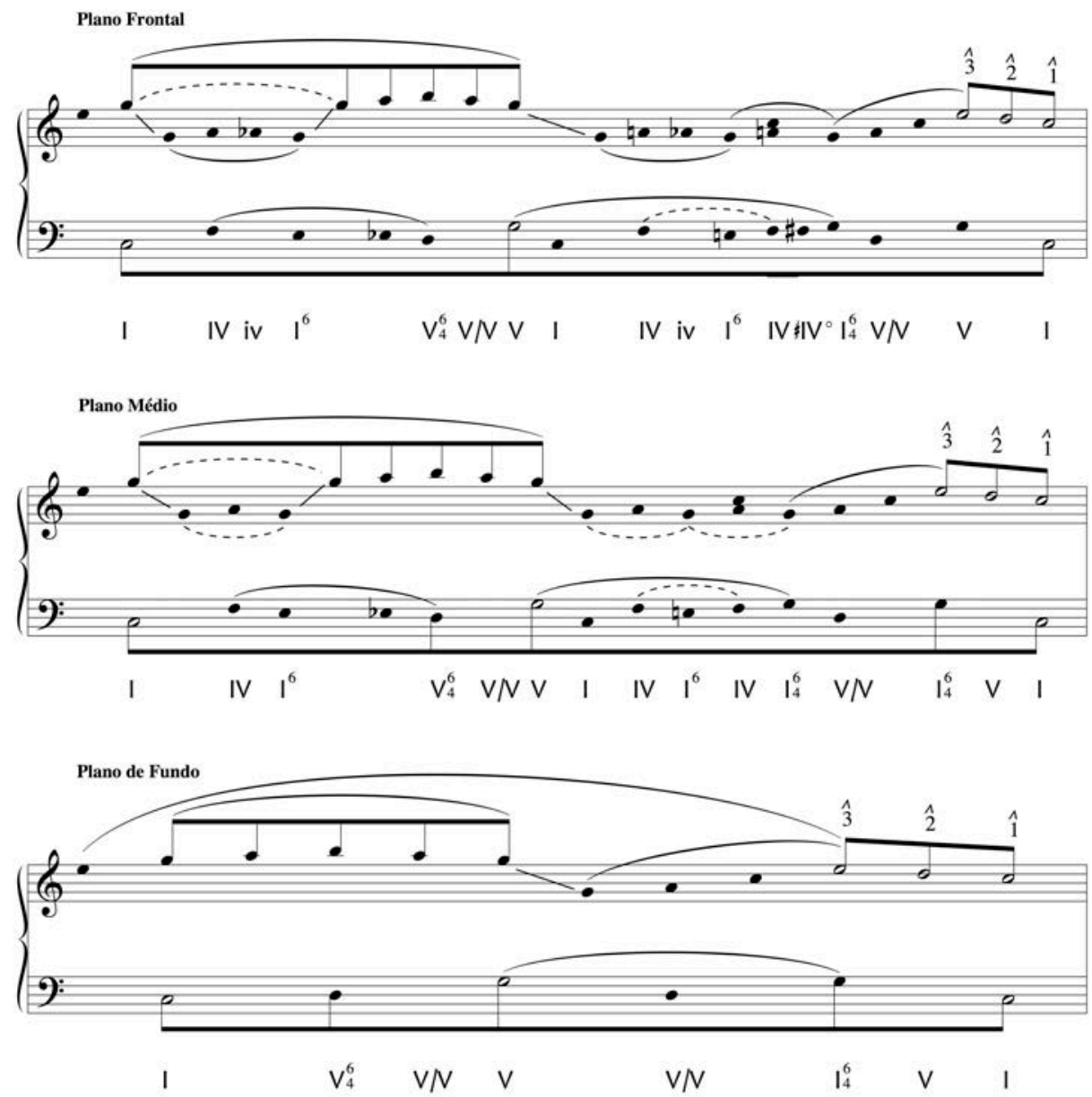
Fig. 16: Plano frontal, médio e de fundo. Seção C.
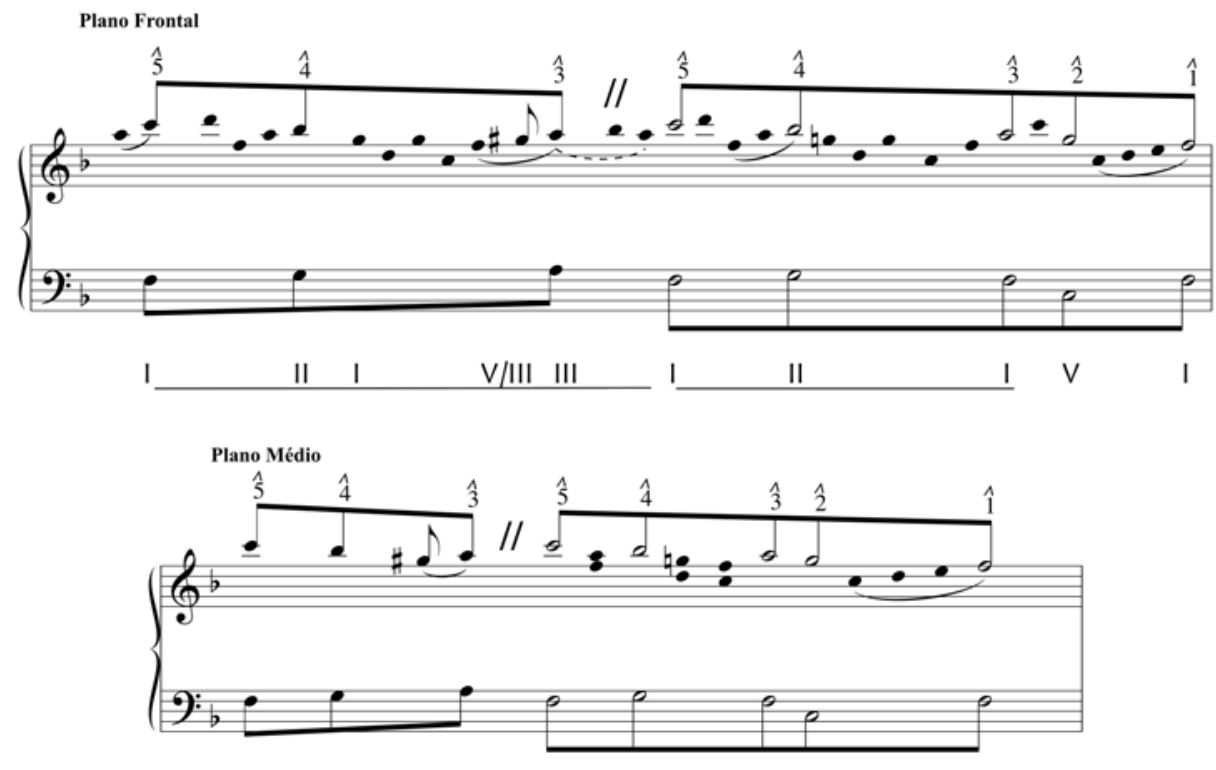

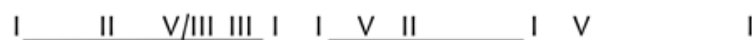

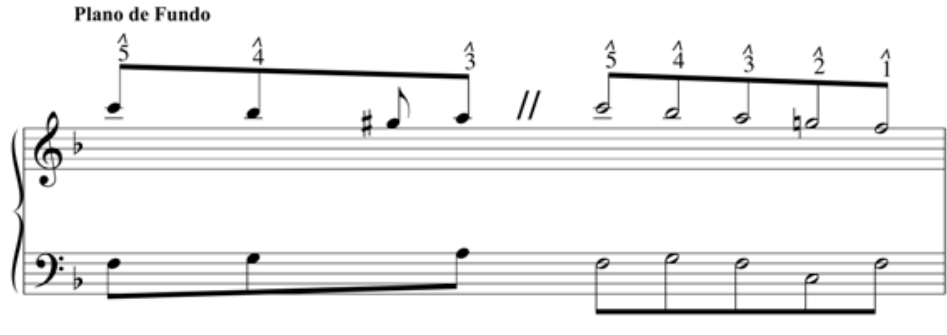

I_III I I I I V V I 
Fig. 17: Plano Frontal, médio e de fundo. Seção D.
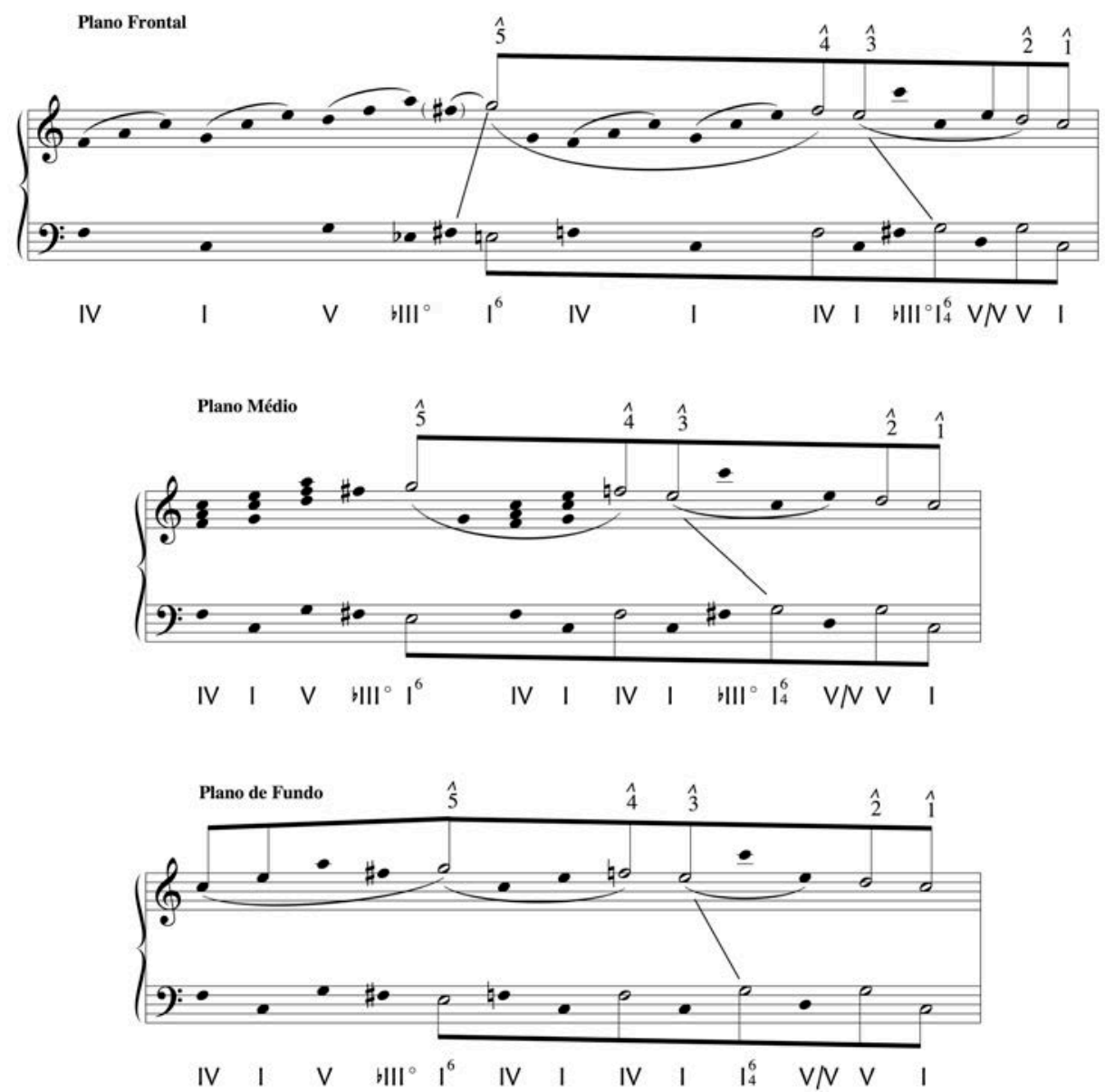

\section{Conclusão}

Apesar de o gênero aqui estudado ser basicamente rítmico e não apresentar desenvolvimento contrapontístico, constatou-se que os diversos tópicos abordados da teoria neo-schenkeriana podem ser identificados neste tipo de repertório. Mesmo não se tratando de uma metodologia que privilegia o motivo um dos traços mais marcantes da estrutura musical de ragtime -, a aplicação da análise neo-schenkeriana para o estudo da peça The Entertainer nos permitiu 
observar certas técnicas de progressão linear que atuam estruturalmente em vários trechos, trazendo alguma coerência e organização interior às seções da obra.

As reduções de ordem prática foram fundamentais para que pudéssemos evidenciar alguns processos que são articulados nos planos médio e de fundo, especialmente técnicas de prolongamento e progressão linear. Foi o caso, por exemplo, dos quatro primeiros compassos de $\mathrm{A}$, onde pode-se constatar técnicas de ascensão inicial, desdobramento, prolongamento, ligação, transferência de registro e transferência de registro através de dobramento em oitava. A cada recorte de quatro compassos, identifica-se diversas técnicas que são incluídas nos gráficos de cada seção e que formam o "esqueleto da peça".

O método de análise neo-schenkeriana aplicada ao ragtime pode ser vista também como um recurso a compositores e arranjadores. Como foi demonstrado, através de reduções pode-se chegar a linhas instrumentais estilisticamente interessantes para acompanhamento e contraponto, sem que a música soe descaracterizada. Novos arranjos instrumentais podem ser criados a partir das partitura originais de piano, uma prática comum durante os anos em que o ragtime predominou como principal manifestação musical original norteamericana.

Enquanto Fraga (2009, p. 28) aponta a harmonia e o contraponto como os principais formadores da progressão linear, ao final deste trabalho pode-se afirmar que o ritmo possui um importante papel na compreensão do repertório de ragtime, muito embora o ritmo seja tratado em análise neo-schenkeriana apenas em técnicas reducionistas. A respeito desta questão, os estudos teóricos sobre ritmo de autores como Lester (1989), Berry (1987) e Kostka (2006) podem suprir esta deficiência apresentada pela metodologia aqui empregada.

Vale também ressaltar que algumas técnicas não foram encontradas ao término da análise, como a permuta. A ausência dessas técnicas podem ser justificadas pelo fato de o ragtime ser um gênero essencialmente rítmico e pouco contrapontístico. Entretanto, a maioria das técnicas abordadas foi identificada em todas as seções, o que nos revela que o método neo-schenkeriano pode ser uma metodologia analítica eficaz ao estudo do ragtime. Os gráficos finais apresentados satisfazem as premissas neo-schenkerianas. 
O ragtime, como diversos outros gêneros populares, carece de metodologia específica de análise musical e de trabalhos que o abordem enquanto objeto de análise. Muito embora a formulação de uma teoria analítica que contemple a música popular esbarre na diversidade e na especificidade de seus sub-gêneros, o modelo de análise neo-schenkeriana não deve ser descartado: é uma alternativa que, sem dúvida, se oferece como uma ferramenta à apreciação e à performance musical, possibilitando ao ouvinte e também ao músico uma experiência musical diferente.

\section{Referências}

BERLIN, Edward. King of ragtime: Scott Joplin and his era. New York, Oxford University Press: 1994.

. Verbete "Ragtime". In: The new Grove dictionary of music and musicians.

2. ed. London: Macmillan, 2001.v. 20.

BERRY, Wallace. Structural Functions in Music. NY: Dover, 1987.

CAPUZZO, Guy. Sectional Tonality and Sectional Centricity in Rock Music. In: Music Theory Spectrum, Vol. 31, No. 1, p. 157-174, Spring 2009.

DENNISON, Sam. Verbete "Coon Song”. In: The New Grove Dictionary of Music and Musicians. 2. ed. London: Macmillan, 2001. v. 6.

FRAGA, Orlando. Progressão Linear: uma breve introdução à teoria de Schenker. Curitiba: Editora do Departamento de Artes da UFPR, 2009.

GILBERT, Steven. Gershwin's Art of Counterpoint. In: The Musical Quarterly, Vol. 70, No. 4, p. 423-456, Autumn, 1984.

JOPLIN, Scott. The Best of Scott Joplin: A Collection of Original Ragtime Piano Compositions (Special collector's ed., [New ed.].). Charles Hansen Music \& Books, 1973.

KOSTKA, Stefan. Materials and Techniques of Post-Tonal Music. 4 ed. Boston: Pearson, 2012.

LARSON, Steve. Schenkerian Analysis of Modern Jazz: Questions about Method. In: Music Theory Spectrum, Vol. 20, No. 2, p. 209-241, Autumn, 1998.

LESTER, Joel. Analytic Approaches to Twentieth-Century Music. NY: W. W. Norton, 1989.

MOORE, Allan. Rock, The Primary Text: Developing a Musicology of Rock. Buckingham and Philadelphia: Open University Press, 1993. 
ROTHSTEIN, William. Articles on Schenker and Schenkerian Theory in "The New Grove Dictionary of Music and Musicians", 2nd Edition by Stanley Sadie. Journal of Music Theory, Vol. 45, No. 1. p. 204-227. Spring, 2001.

SALZER, Felix. Structural hearing: Tonal coherence in music. NY: Dover Pub., 1962.

SCHENKER, Heinrich. Harmony. Chicago: University of Chicago Press, 1980.

SHALL, Arnold. Black popular music in America. New York: Collin Macmillan, 1986.

STRUNK, Steven. Notes on Harmony in Wayne Shorter's Compositions, 1964-67. In: Journal of Music Theory, Vol. 49, No. 2, p. 301-332, Fall, 2005.

ZAK III, ALBIN. Bob Dylan and Jimi Hendrix: Juxtaposition and Transformation "All along the Watchtower". In: Journal of the American Musicological Society, Vol. 57, No. 3, p. 599-644, Fall 2004. 